\title{
A Conversation with Michel Goedert
}

\author{
INTERVIEWER: JAN WITKOWSKI \\ Cold Spring Harbor Laboratory
}

\begin{abstract}
Michel Goedert is a Programme Leader at the Medical Research Council Laboratory of Molecular Biology in Cambridge, United Kingdom.
\end{abstract}

Jan Witkowski: Michel, we first met in 1990.

Michel Goedert: It was probably even earlier. I believe we first met at the conference on "The Molecular Biology of Alzheimer's Disease," at Banbury in April 1988, which was my first meeting on Alzheimer's disease. We (Aaron Klug, Claude Wischik, and I) reported the presence of tau protein in paired helical filaments. Our papers had been accepted for publication, but they hadn't been published yet. So the work came as a surprise to many of the people who were there, because they didn't know we were doing this. Today, the 1 st of June, it is exactly 30 years since the first of those three papers was published.

Jan Witkowski: That was your first venture into structural studies in Alzheimer's?

Michel Goedert: Yes. Alzheimer's disease is defined neuropathologically by the presence of abundant plaques and tangles in neocortex. It wasn't known until the 1980s what they consist of. Plaques are made of a peptide called $\beta$-amyloid, and tangles are made of tau protein. The work we described at the Banbury conference was the first direct demonstration that tau is an integral component of the intracellular filaments of Alzheimer's disease.

Jan Witkowski: It was a very controversial field for quite a while.

Michel Goedert: Yes. The first controversy was about tangle composition. Some people believed that $\beta$-amyloid was the major component of both plaques and tangles. After that was shown to be tau for tangles, the business of what was more important became an issue. For that, you need human genetics. In 1991, mutations in the amyloid precursor protein gene were described by others in familial forms of Alzheimer's disease, but only in 1998 were tau gene mutations found in some frontotemporal dementias. During those 7 years, working on tau was not the easiest proposition in the world. Now, things are calmer and both $\beta$-amyloid and tau are believed to be good therapeutic targets.

Jan Witkowski: One of the controversies was about how it was that nerve cells died. Did they die because of these proteins, or were plaques and tangles a consequence of the cell dying?

Michel Goedert: This controversy applies to all neurodegenerative diseases with abnormal inclusions. The fact is that in familial forms of disease, which are relatively rare, but you can find out their causes, and I would argue in all cases of neurodegenerative diseases, inclusion formation is a bad thing. Probably, the presence of inclusions in nerve cells over long periods of time is sufficient to kill those cells. But, unless you've found all the mechanisms that do this, it's always possible to say that it may not be like that. But I think the argument is quite strong. You have mutations in the amyloid precursor protein gene in cases of Alzheimer's disease and mutations in the tau gene in forms of frontotemporal dementia. Mutations in the $\alpha-$ synuclein gene cause familial forms of Parkinson's disease and dementia with Lewy bodies, whereas mutations in the prion protein gene give rise to Gerstmann-SträusslerScheinker syndrome and some cases of Creutzfeldt-Jakob disease. I would argue that the ordered assembly of those proteins causes these diseases.

Jan Witkowski: So the fact that you've got mutations in these genes producing the abnormal protein in the first place is indicative that that's the causative agent.

Michel Goedert: I think that's strong evidence. In general, these cases are less than $10 \%$ of the total...

\section{Jan Witkowski: Familial ones?}

Michel Goedert: Yes, with the exception of Huntington's disease, which is always familial, but has also inclusions. What one does in the other cases, where there's 10 or less percent of familial cases, one extrapolates to the sporadic forms and the question is whether this is permissible. I believe that it is. But then the question arises, whether it's allowed to $100 \%$, and that I don't know. But I think overall the evidence is quite strong.

Jan Witkowski: In 1988 were you doing electron microscopy? Were you doing structural studies of those proteins?

Michel Goedert: The work was a mixture of molecular biology, biochemistry, and structural studies. One had to

(C) 2018 Goedert. This article is distributed under the terms of the Creative Commons Attribution-NonCommercial License, which permits reuse and redistribution, except for commercial purposes, provided that the original author and source are credited. 
get peptide fragments that one could relate back to the paired helical filaments, which one could see only by electron microscopy. As soon as you take the filaments apart, you can't see them anymore. So you needed a label that allowed you to see filaments by electron microscopy and their fragments by western blotting. That's where monoclonal antibodies came in. Cesar Milstein was involved. We were working in the laboratory where these technologies had been invented. It was clear that the peptide fragments that we got had come from paired helical filaments. John Walker was also at the LMB. He was doing protein sequencing on this material, so we got partial amino acid sequences. We cloned and sequenced the corresponding cDNAs and found that they encoded tau.

Jan Witkowski: That work is something of a contrast with your current research.

Michel Goedert: Yes. The initial work was at the level of product analysis. We subsequently were part of the work showing that the formation of tau inclusions was relevant, because of mutations in the tau gene. Then we were part of studies showing the prion-like properties of assembled tau, which is still a very active field. More recently, we used cryo-electron microscopy (cryo-EM) to obtain the high-resolution structures of tau filaments from Alzheimer's disease. That was published last year. We've done more recent work on Pick's disease, which is not yet published. These studies have shown that there are distinct conformers of assembled tau in different diseases, which some people also refer to as protein strains, and which one believes may give rise to the different diseases. Sometimes people ask, "Why are they not the same disease, since they all have tau inclusions?" And maybe that has to do with the fact that there are distinct conformers of assembled tau that give rise to different diseases.

Jan Witkowski: Is that similar to prion strains?

Michel Goedert: Yes. It's formally analogous. I believe that ultimately if you want to define a conformer or strain, you need high-resolution structural information. Before cryo-EM, it was possible to get resolutions of 20-30 $\AA$, but now you can get resolutions of $3-4 \AA$ for these filaments. That's a big step forward.

Jan Witkowski: What things did cryo-EM show you that were unexpected, or that you had expected and that confirmed your suspicions about?

Michel Goedert: Tau isoforms have three or four repeat motifs, and one knew that the core of the tau filaments of Alzheimer's disease is located somewhere in those repeats, but one didn't know in which. One surprise was that the core consists of repeats three and four, plus at least 10 amino acids after repeat four. The exclusion of the aminoterminal part of repeat two was unexpected. Another surprise was the combined presence of several $\beta$ sheets and one $\beta$ helix in the protofilament core. In Pick's disease, there's only three-repeat tau in the inclusions. And that's what we observe. But we see exactly what's present and can also explain why there are only three-repeat, not four-repeat tau inclusions in Pick's disease, because the extra repeat could not fit into that sort of structure. So it tells you quite a lot. It obviously doesn't lead to any sort of treatment, but it gives you a solid baseline from where to start. In principle, you can do the same for $\beta$-amyloid and $\alpha$-synuclein inclusions. It is now possible to determine high-resolution structures of filaments from human brain without any intermediary steps.

Jan Witkowski: You mentioned that this work doesn't immediately point to therapies. Has it pointed toward lines of research that might be followed more clearly to a treatment?

Michel Goedert: Yes. I believe that what one should aim for in the long run is to prevent these diseases, because by the time somebody has symptoms, even mild ones, there may already be many inclusions in the brain. In order to prevent them from forming in large numbers, you obviously need something that you can give to people, but you must also be able to identify people at risk, because only $10 \%$ of cases or less are inherited. To identify people at risk, you need biomarkers, probably something like PET [positron emission tomography] ligands. Knowing the structures, in principle, should allow you to get better and more specific PET ligands. That's one thing.

The second thing is that cryo-EM can only tell you what's there at the end; it doesn't tell you what was there at the beginning. But we believe that by knowing more about what's present at the end for different diseases, we may be able to design experiments in animals and other models to study what may have been there at the beginning. It's still early days, but I think in the long run this work will help a lot.

Jan Witkowski: You mentioned prevention and early diagnosis. Is it known what types of things lead to these sporadic cases? What are the precipitating factors?

Michel Goedert: I believe that what causes diseases is the abnormal assembly of these proteins. But what leads to their assembly is another question. We just don't know. It's also the question of what's the first event, whether we will ever know what that is. Assembly may happen almost stochastically in a brain, and then, given enough time, the pathology may spread. Understanding mechanisms of this so-called prion-like spreading is important because it may allow one to prevent the appearance of symptoms. The first events probably do not lead to symptoms, so people can have small numbers of deposits in their brains without having symptoms of disease. But there could be multiple reasons that lead to the first events. We don't know.

Jan Witkowski: You're talking about cell-to-cell spreading. John Collinge did a meeting at Banbury on transmissible aspects of prion diseases: the idea that Alzheimer's disease could be transmitted in some way.

Michel Goedert: I think it's true to say that when you have inclusions in the brain, their propagation is similar to that of prions. But that does not mean that Alzheimer's disease 
or Parkinson's disease is infectious. That's another issue, but I think the mechanisms involved in the spreading of disease through the nervous system may be similar in prion diseases and other neurodegenerative conditions. This is a good case for arguing that one should work on things that are biologically interesting, even when they're rare. Prion diseases are rare, but they keep throwing important light on mechanisms which may well be very common. 


\section{$\$_{\text {CSH\& }}^{\infty}$ Cold Spring Harbor Symposia SYMPOSIA On Quantitative Biology}

\section{A Conversation with Michel Goedert}

Cold Spring Harb Symp Quant Biol 2018 83: 252-254 originally published online January 14, 2019

Access the most recent version at doi:10.1101/sqb.2018.83.037358
Creative This article is distributed under the terms of the
Commons http://creativecommons.org/licenses/by-nc/4.0/, which permits reuse and
License redistribution, except for commercial purposes, provided that the original author and source are credited.

Email Alerting Receive free email alerts when new articles cite this article - sign up in Service the box at the top right corner of the article or click here. 